\title{
A prática docente e as relações de gênero e sexualidades: conversando com professoras e professores
}

\section{Teaching practice and gender relationships and sexualities: talking with teachers and teachers}

\section{Práctica docente y relaciones de género y sexualidades: hablando con profesoras y profesores}

\author{
Anderson Ferrari* \\ Claudete Imaculada de Souza Gomes** \\ Cláudio Magno Gomes Berto***
}

\section{Resumo}

Qual tem sido o trabalho com gênero e sexualidade realizado por professores e professoras em 3 escolas na cidade de Juiz de Fora? Essa é a pergunta foco que direciona as análises neste artigo em torno das questões surgidas em uma pesquisa de mestrado realizada entre os anos de 2015-2016. Como gênero e sexualidade são organizadores sociais, resultado de construção histórica e cultural, ouvir e dialogar com professoras e professores é reforçar a ideia de que escolas não são essências, mas fruto de relações entre indivíduos e sociedade. Nesse sentido, estamos assumindo a perspectiva teórico-metodológica pós-estruturalista, influenciada pelos estudos foucaultianos, principalmente a partir da noção de problematização, vinculada à história do pensamento, que, não se propondo a oferecer soluções, proporciona a oportunidade de ampliar o debate sobre pesquisa no campo educacional. Como processo metodológico aplicamos um questionário nas escolas da cidade para identificar que professoras e professores assumiam fazer um trabalho com gênero e sexualidade. Dos 36 professores e professoras que assumiram tal trabalho, somente 5 aceitaram participar dos grupos focais em que discutimos as respostas ao questionário. São com essas falas construídas nos grupos focais que vamos trabalhar. Dois aspectos aparecem como resultados das conversas. O primeiro é a evidencia de que as professoras e os professores adquirem e colocam em prática conhecimentos que se referem às relações de gênero e sexualidade e conseguem fazer articulações com o seu fazer docente. O segundo é a demonstração de que as escolas que trabalham realizam um trabalho com gênero e sexualidade.

Palavras-chave: Escolas. Gênero. Sexualidades.

Recebido em 28/02/2019 - Aprovado em 29/07/2019

http://dx.doi.org/10.5335/rep.v27i1.10583

Doutor em Educação pela Universidade Estadual de Campinas (Unicamp, Brasil). Professor adjunto de Ensino de História da Faculdade de Educação da Universidade Federal de Juiz de Fora (UFJF, Brasil). ORCID https://orcid.org/00000002-5681-0753. E-mail: aferrari13@globo.com

** Mestre em Educação pela Universidade Federal de Juiz de Fora (UFJF, Brasil). Professora de Ciências e Biologia na educação básica, Secretaria de Estado de Educação (SEE/MG), e na formação de professores na Faculdade de Educação da Universidade Federal de Juiz de Fora (UFJF, Brasil). Professora de Ciências e Biologia no Colégio de Aplicação João XXII/UFJF. ORCID https://orcid.org/0000-0003-2499-9659. E-mail: cl_claudete@hotmail.com

*** Mestre em Psicologia pela Universidade Federal de Minas Gerais (UFMG, Brasil) e integrante do Núcleo de Pesquisas e Práticas em Psicologia Social, Políticas Públicas e Saúde (Núcleo PPS - UFJF) e do Núcleo de Cidadania e Direitos Humanos LGBT (Nuh - UFMG). ORCID https://orcid.org/0000-0002-1660-1519. E-mail: cl-magno@hotmail.com 


\section{Abstract}

What has been the work with gender and sexuality performed by female teachers in 3 schools in the city of Juiz de Fora? This is the focus question that directs the analyzes in this article around the issues raised in a master's research conducted between 2015-2016. As gender and sexuality are social organizers, the result of historical and cultural construction, listening and dialogue with teachers is to reinforce the idea that schools are not essences, but the result of relationships between individuals and society. In this sense, we are taking the poststructuralist theoretical-methodological perspective, influenced by Foucaultian studies, mainly from the notion of problematization, linked to the history of thought, which, not proposing to offer solutions, provides the opportunity to broaden the debate about research in the educational field. As a methodological process we applied a questionnaire in the city's schools to identify which teachers assumed to do work with gender and sexuality. Of the 36 teachers who took on such work, only 5 agreed to participate in the focus groups in which we discussed the questionnaire responses. It is with these lines built in focus groups that we will work. Two aspects appear as a result of conversations. The first is the evidence that teachers have acquired and put into practice knowledge that refers to gender relations and sexuality and can articulate with their teaching practice. The second is the demonstration that working schools do gender and sexuality work.

Keywords: schools, gender, sexualities

\section{Resumen}

¿Cuál ha sido el trabajo con género y sexualidad realizado por maestras en 3 escuelas de la ciudad de Juiz de Fora? Esta es la pregunta principal que dirige los análisis en este artículo en torno a los temas planteados en una investigación de maestría realizada entre 2015-2016. Como el género y la sexualidad son organizadores sociales, el resultado de la construcción histórica y cultural, la escucha y el diálogo con los docentes es reforzar la idea de que las escuelas no son esencias, sino el resultado de las relaciones entre los individuos y la sociedad. En este sentido, estamos tomando la perspectiva teórico-metodológica postestructuralista, influenciada por los estudios foucaultianos, principalmente desde la noción de problematización, vinculada a la historia del pensamiento, que, al no proponer soluciones, brinda la oportunidad de ampliar el debate sobre investigación en el campo educativo. Como proceso metodológico, aplicamos un cuestionario en las escuelas de la ciudad para identificar qué maestros asumían que trabajaban con género y sexualidad. De los 36 maestros que asumieron dicho trabajo, solo 5 aceptaron participar en los grupos focales en los que discutimos las respuestas al cuestionario. Es con estas líneas integradas en grupos focales que trabajaremos. Dos aspectos aparecen como resultado de las conversaciones. La primera es la evidencia de que los maestros han adquirido y puesto en práctica conocimientos que se refieren a las relaciones de género y la sexualidad y que pueden articularse con su práctica docente. La segunda es la demostración de que las escuelas que trabajan hacen trabajo de género y sexualidad.

Palabras-clave: Escuelas. Género. Sexualidades.

\section{Introdução}

Segundo Joan Scott (1995), podemos e devemos assumir o gênero como categoria de análise, o que significa dizer que podemos olhar o mundo e problematizar a realidade a partir das relações de gênero. É possível conceber, ainda, os gêneros como organizadores sociais. Tomando como ponto de partida essa proposta, gênero e sexualidade variam ao longo da história e se referem ao que a sociedade atribui como feminino ou masculino. Nas ações docentes, a construção de gênero se dá co- 
tidianamente, mesmo que não haja uma intenção ou clareza disso por parte das/os professoras/es. As aulas colocam em circulação diferentes noções de gênero e seus atravessamentos com as sexualidades, que são atribuídas aos sujeitos. Os gêneros estão presentes nas escolhas de imagens, textos, cores, lugares, músicas e performances para afirmar essa demarcação entre o que constitui homens e mulheres, seus corpos e desejos.

No Brasil, a relação entre gênero e sexualidade diz de um embaralhamento entre eles, visto que ser homem ou mulher significa ser heterossexual (LOURO, 1997). A sexualidade passa a ser um componente de constituição do gênero. Nesse sentido, é importante deixar claro o que estamos entendendo como sexualidade. Estamos nos inspirando em Michel Foucault (2011) que entende sexualidade como dispositivo. Para o autor, desde o século XVI o Ocidente moderno ligou o sexo à verdade dos sujeitos, de maneira que somos incitados a confessar (pelo menos para nós mesmos) sobre os nossos desejos, paixões, emoções, num processo de exame de consciência, vigilância para saber e responder o que somos. "E, através desse dispositivo, pôde aparecer algo como a "sexualidade" enquanto verdade do sexo e de seus prazeres" (FOUCAULT, 2011, p. 67). Afirmar que a sexualidade como um dispositivo é uma forma de entendê-la como resultado de uma rede heterogênea de relações de poder que envolve práticas discursivas e não discursivas. As escolas são parte dessa rede e desse processo de constituição de sujeitos nos atravessamentos entre gênero e sexualidade.

Além do aspecto da construção histórica, outro ponto de ancoragem do gênero é o seu entendimento como um conceito relacional, que traz a ampliação das discussões não só em torno da constituição das feminilidades, mas também da constituição das masculinidades, uma vez que homens e mulheres são constituídos a partir das interações e referências recíprocas que ambos estabelecem. Judith Butler (2015) nos convida a pensar como vamos construindo gênero como se ele sempre estivesse lá, pronto para ser acionado. Problematizando essa forma de lidar, a autora descreve como gênero é um processo que não tem nem origem e nem fim, de maneira que é algo que fazemos e não algo que somos. Gênero e sexualidade não são inatos. É quando gênero se afasta daquilo que estabelecemos como sua sexualidade "natural" que parece ser o "problema". O sentido de normalidade também ocorre no encontro entre gênero e sexualidade, de tal maneira que ser homem ou mulher está diretamente ligado a ser heterossexual. A heterossexualidade é tomada como a norma. As diferenças são construídas discursivamente no distanciamento a essa norma. A noção de "problema" se relaciona com o entendimento do que Butler (2006) vai denominar de "matriz heterossexual", como aquela que 
coloca em circulação a "[...] grade de inteligibilidade cultural por meio da qual os corpos, gêneros e desejos são naturalizados” (BUTLER, 2015, p. 216).

Para desenvolver essa ideia, Butler (2015) analisa as estruturas jurídicas contemporâneas como aquelas que cristalizam as identidades de gênero e sexualidade nos termos da coerência da matriz heterossexual. Dessa forma, a presunção de uma identidade masculina e feminina estaria servindo também para excluir outros corpos, sujeitos e identidades que não se enquadram nessa normatividade. Nosso interesse é problematizar esse jogo de construção das relações de gênero no encontro com as sexualidades nas falas das professoras/es.

Para isso, vamos tomar as falas de cinco professoras/es como provocativas para nossa escrita. Cinco participantes de uma pesquisa de mestrado - realizada entre 2015 e 2016 - que tinha como objetivo geral a problematização dos saberes e práticas a respeito das relações de gênero e sexualidades colocadas em vigor nas aulas. Na tentativa de identificar professoras/es que afirmavam trabalhar com essas temáticas, foi elaborado e aplicado um questionário com quatro questões abertas ${ }^{1}$ a docentes de três escolas públicas municipais de Juiz de Fora-MG que aceitaram participar dessa fase inicial da pesquisa. De posse da análise dos questionários, convidamos as/os 36 professoras/es que responderam a participar de grupos focais em que discutiríamos a relação entre gênero, sexualidades e educação a partir do agrupamento das respostas em categorias de análise como "respeito", "preconceito", "diversidade", "conteúdo", "silêncios", "formação docente", que apareceram nas respostas. Portanto, este texto é um convite a pensar as questões que organizam as falas das/os docentes das três escolas participantes da pesquisa. De um total de 36 professoras/es que responderam ao questionário, somente cinco aceitaram e assinaram o termo de consentimento: Luiz ${ }^{2}$, professor de Inglês; Ana e Paulo, professores de História; Marília, de Geografia e Cristiano, de Educação Física. Docentes de faixas etárias variadas, com tempo de trabalho que oscilava entre 8 e 23 anos.

$\mathrm{O}$ foco de problematização que elegemos para organizar este artigo foi o encontro entre a ação docente e a insegurança com o trabalho, levando-nos a pensar o aspecto paradoxal e complexo do trabalho com gênero e sexualidade na sala de aula. Paradoxal porque, ao mesmo tempo em que reconhecem a importância do trabalho, as/os professoras/es não conseguem identificar o protagonismo na ação, não percebendo o gênero e a sexualidade como atravessados nas suas disciplinas. Tais pontos apareceram na pesquisa a partir da convocação das/os professoras/es para que nos contassem sobre o faziam, como faziam e seus desdobramentos na relação com as temáticas e com os desafios e potencialidades da ação docente. É 
relevante dizer, ainda, que as narrativas se referem a situações e atividades ocorridas no cotidiano dessas três escolas pesquisadas, ou seja, não se pretende uma generalização da educação municipal de Juiz de Fora. A organização da escrita diz dos tópicos relacionados diretamente aos assuntos mais abordados, aos quais as/ os docentes dedicaram maior tempo e/ou demonstraram maior empenho e atenção.

Diante dessas colocações introdutórias, queremos situar nossa escrita na perspectiva dos estudos foucaultianos, no trabalho com a noção de problematização como um caminho para frente, vinculado à história do pensamento, e que não se propõe a oferecer soluções, proporcionando a oportunidade de ampliar o debate sobre pesquisa no campo educacional e buscando a problematização como possibilidade de fazer pesquisa em educação. A problematização está inscrita na história do pensamento para questionar por que pensamos o que pensamos, como construímos nossas formas de pensar e agir e como somos resultados desses saberes e poderes. A perspectiva pós-estruturalista amplia o conceito de poder como proveniente não somente das esferas do Estado, mas presente "em toda parte".

Segundo Guilherme Lima Cardozo (2014, p. 128), essa perspectiva inova,

[...] ao trazer ao campo as questões de identidade/alteridade/diferença, considerando a subjetividade dentro da pesquisa científica, dando espaço às relações de saber e poder influenciando na cultura e na sociedade, onde tensões advindas de gênero, raça, etnia e sexualidade trazem à tona o multiculturalismo. Sobre isso, o pós-estruturalismo trouxe colaboração ímpar à educação.

A pesquisa e seus achados não necessariamente "representam aproximação da verdade, mas uma de suas múltiplas possibilidades" (COSTA, 1996, p. 5) de conhecer e construir sentidos para o que é realizado pela escola e pelas/os professoras/es. Assim, nossa intenção é contribuir para as discussões do campo de conhecimento de Gênero, Sexualidade e Educação, trazendo para a escrita o que surge das narrativas de professoras/es quando são convidadas/os a refletir sobre o fazer docente nas escolas.

\section{0 que aparece quando se fala de gênero e sexualidades com docentes?}

Abrir a escuta às/aos professoras/es exige certo cuidado e atenção. Cuidado para buscar as formas de organização dos sujeitos pela/na fala, pelas/nas formas de pensar e dizer, de concordar e discordar do outro, de maneira que possam ficar à vontade para se colocarem em diálogo. A análise das falas também demanda atenção para sentir e dar lugar às resistências, aos detalhes e para aguçar os sentidos 
e ver o que comumente não conseguimos enxergar. Cabe ressaltar, portanto, como aponta Alfredo Veiga Neto (2013, p. 112-113):

A leveza de um estilo de investigação que, mesmo rigorosa, se abre para suas fronteiras na esperança de ultrapassar a si mesma e de conseguir enxergar nas regiões de indecidibilidade que até então permaneciam na penumbra [...] usando o que Foucault nomeia como uma "maneira de ver as coisas", "um modo de ver".

Para Veiga Neto (2013, p. 114), o comprometimento de Foucault “está em colocar sob escrutínio práticas que permitem entender as relações do ser consigo e com os outros”. Assumindo essa perspectiva de análise, procuramos entrever nas/ os parceiras/os de pesquisa essas diferentes e ricas formas de se relacionar com os saberes, os acontecimentos e os discursos presentes em suas escolas. As respostas das/dos professoras/es possibilitaram trazer para a discussão suas/seus alunas/os, as vivências no/com o cotidiano da escola, para interrogar como as/os professoras/es se veem em relação a suas práticas, diante da provocação desencadeada pelas falas de seus companheiros de trabalho, de seus pensamentos e ações em seus contextos profissionais. Nesse sentido, foi importante deixar que cada uma/um definisse, entre os termos e assuntos sugeridos a partir das respostas dadas aos questionários, em que direção gostaria de conduzir a conversa.

Durante os grupos focais, o ponto mais marcante para as/os professoras/es foi a recorrência à palavra "respeito" quando falavam do trabalho com gênero e sexualidade. Partimos, então, da ideia de "respeito", que já havia despertado nossa atenção desde as primeiras análises, ainda nos questionários. O uso da palavra "respeito", relacionada às diferenças, foi recorrente, quando perguntadas/os sobre a convivência nos espaços das escolas. O que significa esse "respeito"? Porque essa palavra surge quando perguntamos sobre a convivência das diferenças na escola? O professor Paulo afirma que "de início o que aparece não é o respeito, mas o desrespeito às diferenças. Uma orelha maior, um nariz ou o cabelo, tudo vira motivo de piada", ao que a professora Marília complementa dizendo que "o visual atrai mais", identificando, na prática discriminatória, algo comum direcionado à aparência das/dos alunas/os e outras pessoas presentes nesses espaços. Segundo Paulo, "o desrespeito aparece e a partir dele começa a se trabalhar a questão do respeito, desde a aparência até a opção sexual”. O docente sinaliza que é importante estar atento às temáticas que surgem nas conversas cotidianas de alunas e alunos e, partindo delas/es, suscitar discussões que coadunem com o que cada uma/um vive na escola e na sociedade. 
Respeito é acionado para falar das relações estabelecidas neste espaço de disputa e negociação que é a escola. O respeito é entendido como necessário para as relações entre alunos e alunas como adequadas, pacíficas, sem conflitos e sobretudo, como forma de aceitação das diferenças. Respeito pode ser entendido como resultado das relações de saber-poder em Foucault (2011). Aquilo que sabemos diz de formas de conhecer ancoradas historicamente e que nos constitui. Somos sujeitos, resultado de saberes, atravessados por relações de poder, de maneira que respeitar alguém está diretamente ligado a construção de si e do outro.

As falas demonstram que as/os professoras/es estão atentos ao que ocorre na escola, identificam situações em que respeito e desrespeito estão em negociação entre os alunos e as alunas, percebendo-se com interlocutores importantes para problematizar essas construções. Também conseguem citar os aspectos causadores do que estão classificando como desrespeito. Enfim, eles e elas constroem um quadro que aponta para uma dicotomia representada pelos termos respeito/desrespeito, que não havia aparecido nos questionários respondidos. Ampliando um pouco mais a análise, podemos sugerir que as/os alunas/os constroem suas identidades (e seus pertencimentos) nas diferenças. Isso chega à escola, lugar de confronto e negociação. A/O professora/or age e, ao agir, ela/e põe em prática um projeto de "ser professor(a)", "ser escola" e do aluno(a) "ideal". Para esses docentes, a ética e o respeito ao outro e às suas subjetividades devem ser praticados por todos e todas, alcançando professoras/es e alunas/o, assim como sugerem que o desrespeito também vem de ambos, o que deve ser repensado, conforme Marília e Paulo. Tal ponto de vista é compartilhado pelo professor Luiz, que declara que

[...] o respeito deve ser ponto de partida em qualquer escola, pois os professores precisam saber que os indivíduos têm suas escolhas [...] a questão da homossexualidade, por exemplo, a gente percebe que tem muita criança que tem uma tendência ao homossexualismo e isso...o ser humano tem que ter o direito de nascer do jeito que nasceu e ser do jeito que é.

De acordo com essas falas, é possível inferir que, nessas escolas, a partir desses docentes, existe a preocupação em desenvolver, durante suas aulas, a prática do respeito ao outro. Ferrari e Castro (2013b, p. 296) enfatizam a relevância de

[...] deixar claro que os discursos e práticas sobre os quais e desde os quais vamos trabalhar partem do pressuposto de que as sexualidades não são fatos naturais, mas sim resultados de articulação histórica, discursiva e socialmente construída.

Na defesa do respeito, as/os professoras/es demonstram ter conhecimento de que as questões de discriminação e preconceito dizem de construções sociais, daí 
o entendimento sobre a necessidade de a escola implementar ações no sentido de combater práticas que discriminam e desrespeitam, visando à construção de uma sociedade menos preconceituosa e violenta. As narrativas das professoras/es estão ancoradas na concepção de que a escola e a ação docente estão ligadas à construção dos sujeitos. Como reflexo disso, tentam fazer as/os alunas/os se colocarem no lugar do "outro", como percebemos na afirmação do professor Luiz:

Pra mim, tudo passa pelo respeito. [...] eu falo muito com os meninos: "e se fosse com você?" Quem se coloca no lugar [...] Eu sempre falo com eles "se coloque no lugar do outro, independente de que situação seja, antes de julgar, de qualquer coisa, se fosse com você, como você ia reagir a isso?

O professor coloca em prática uma forma de saber que, atravessada por relações de poder, diz dos encontros e desencontros entre sujeitos, buscando promover o combate às discriminações e ao preconceito por meio do incentivo à empatia. Partindo do princípio de que o gênero é um organizador social e de que a escola é produto e produtora dessa divisão binária dos gêneros que marca nossa sociedade, podemos pensar que uma das dificuldades enfrentadas no conjunto respeito/desrespeito diz das relações de gênero. Com isso, queremos dizer que as questões de enquadramento do gênero ocorrem cotidianamente, o que nos convida a pensar os modos como os discursos funcionam para construir sujeitos detentores de um gênero e de uma sexualidade. A necessidade de respeito passa a ser uma reivindicação das professoras e professores como ataque ao desrespeito.

Assim, respeito e desrespeito às expressões de gênero podem ser entendidos como discursos que cumprem alguns propósitos políticos em nomear os sujeitos generificados. Mais do que isso, diz dos embaralhamentos entre gênero e sexualidade. Para Judith Butler (2018), os gêneros são resultados de atos performativos, atos que, insistente e repetidamente, constituem homens e mulheres de acordo com as normas de gênero que cada sociedade vai construindo. A escola e as relações que se desenvolvem no seu interior são parte desse processo de construção de homens e mulheres. Ao se apresentarem no espaço público, de forma geral, e nas escolas, em especial, os corpos generificados não apenas demonstram sua existência, mas reivindicam reconhecimento e valorização, exercendo o direito de aparecer e colocar em prática a liberdade, reivindicando, em última instância, o direito a uma vida que possa ser vivida (FOUCAULT, 2011a).

"Uma vida que possa ser vivida" é uma expressão cunhada por Michel Foucault que nos convida a pensar nos modos de vida que experimentam outras formas de ser e estar no mundo. Inspirado no arcabouço foucaultiano, Jamil Cabral 
Sierra (2013) toma a vida de Gilda, uma travesti que viveu nas ruas de Curitiba da década de 1980 para colocar sob investigação o modo de viver uma vida como sua manifestação da verdade. Sierra (2013) argumenta que o investimento em vidas que possam ser vividas diz do "trabalho de elaboração de uma noção sobre estética da existência e modos de vida para, com isso, arriscar outras experimentações de vivibilidade diante dos limites que individualizam o sujeito na lógica objetivadora das identidades" (SIERRA, 2013, p. 103). Quando o professor Luiz provoca os/as alunos/as a se colocarem no lugar do outro, ele as/os está incitando a viverem outras vidas, outras formas de ser e estar no mundo. Para isso, cada uma/um terá que acionar formas de conhecer sobre o "outro", que possibilitem se aproximar desse outro que é o diferente.

Temos na escola um ambiente fértil, no qual é possível conduzir as mais variadas discussões. As temáticas surgem o tempo todo, cruzando o currículo formal com as demandas trazidas pela comunidade escolar, pelas/os funcionárias/os, pais, alunas/os e docentes que percebem a necessidade de incluir novas problematizações e situações do interesse coletivo. O que as/os professoras/os nos dizem é que a escola não fica limitada aos conteúdos prévios e programados, mas que há um movimento vivo de construção do currículo a partir do que emerge no cotidiano escolar, presente em discussões informais surgidas durante as aulas e/ou no tempo de permanência na escola, elaborando, assim, um currículo oculto. Segundo Marlucy Paraiso e Lucíola Santos,

A expressão "currículo oculto" tem sido muito utilizada, significando o conjunto de normas e valores implícitos nas atividades escolares, porém não mencionados pelos professores ou não intencionalmente buscados por eles. São, portanto, aprendizagens ou efeitos de aprendizagens não intencionais que se dão como resultado de certos elementos presentes no ambiente escolar. É constituído tanto de práticas como de mensagens não explicitadas (SANTOS; PARAÍSO, 1996, p. 84)

A esse respeito, Antonio Flávio Moreira e Vera Candau (2007) acrescentam que rituais e práticas fazem parte do currículo oculto, assim como relações hierárquicas, regras e procedimentos, modos de organizar o espaço e o tempo na escola, modos de distribuir as/os alunas/os por grupamentos e turmas, assim como mensagens implícitas nas falas dos/as professores/as e nos livros didáticos. Esse currículo é o reflexo social e cultural de uma determinada forma de ver o mundo, trazida por todas/os que constroem a educação no dia a dia de cada escola, configurando-se como um instrumento político ligado à ideologia e às relações de poder institucionalizadas nesses grupos e lugares e que se operacionaliza nas salas de aula. 
Para a professora Marília, "a escola reflete tudo, ela é o celeiro, tudo para ali, e é normal que as diferenças apareçam... e por isso eu acho que a escola precisa trabalhar isso". Ao dizer da necessidade de trabalhar com aquilo que chega à escola, Marília se refere a um entendimento do currículo como algo vivo, em construção e imprevisível, capaz de acolher e tratar dos temas e espaços que dialogam com a escola. Recorrentemente, os/as alunos/as trazem temas que entrecruzam com gênero e sexualidade, tais como bullying, preconceito, relações afetivas, dentre outros que convidam as/as professoras/os a abordarem as relações de gênero e sexualidades, assim como a manterem o diálogo aberto para outras questões trazidas para as aulas, tendo "como desafio 'manter viva a pergunta', o que significa que os(as) professores(as) não se tornem a própria 'personificação do conhecimento' sabendo lidar com a dúvida, com as 'novidades' vivenciadas pelos(as) alunos(as)" (FERRARI; CASTRO, 2013a, p. 76).

Ampliando os entendimentos da "necessidade de trabalhar isso", como sugerido pela professora Marília, queremos pensar o porquê de o currículo oficial não contemplar esses temas e como a escola lida com essa ausência. Alexsandro Rodrigues (2009, p. 66) afirma que "as pessoas desconfiam/reagem/resistem a esses efeitos normatizantes de condutas e comportamentos, que são impressos nos textos/discursos do currículo e, ao reagirem, produzem", ajudando-nos a entender os enxertos cotidianos de temas nos currículos praticados, que extrapolam e superam o currículo oficial, buscando atender às demandas de cada escola e de seus sujeitos. $\mathrm{O}$ autor ainda acrescenta que, durante suas vivências nas escolas, as/os professoras/es percebem e sentem que "a partir dos muitos fios de saberes das redes cotidianas do fazer escola, que professores e alunos transgridem o receituário das tecnocracias impressas no currículo prescritivo, oficializado, alterando-o e imprimindo seus significados" (RODRIGUES, 2009, p. 67).

O que as/os professoras/es nos dizem, de forma enfática, é que a escola propõe algo, ela tem um planejamento que se relaciona com o que é oficial, com os currículos, com os limites dos conteúdos e das disciplinas, com a pressão das provas em larga escala. No entanto, esse planejamento não está garantido, sendo, o tempo todo, afetado por aquilo que as alunas e os alunos trazem de fora, que diz dos seus interesses e que, muitas vezes, está ligado às questões de gênero e sexualidades, aos desejos, às paixões, aos conflitos, enfim, algo que é vida, que diz dos sujeitos e suas aproximações e diferenças. Para Anna Paula Vencato (2014, p. 24), 
Embora a existência de diferenças possa ocasionar conflitos na escola, é preciso que tenhamos claro que o problema a ser enfrentado não são as diferenças, mas as desigualdades. Diferenças devem ser entendidas como um sinônimo de riqueza, e devem ser valorizadas dentro da escola e das práticas pedagógicas. É importante que estejam incluídas nos conteúdos, currículos, debates e nas relações entre os diferentes sujeitos que circulam nesse ambiente. É preciso compreendê-las, conhecê-las e respeitá-las.

Ao trabalhar com as falas das professoras/es, queremos tomá-las como convite ao pensamento, à história do pensamento que organiza nossas formas de ver o mundo e de lidar com os sujeitos e conosco. É possível pensar novas abordagens a partir da reação docente a episódios que categorizam, classificam e excluem. Para Ferrari e Castro (2013b, p. 316),

A formação docente pode ser um espaço/tempo em que os/as professores/as têm a oportunidade de desconstruir concepções naturalizadas, abalar certezas prontamente construídas, revisar seus próprios valores, colocá-los sob suspeita, repensar os currículos escolares e as práticas pedagógicas, com vistas à ampliação das noções de saberes legítimos.

O olhar docente diz da percepção das possibilidades que cada sujeito traz consigo e que exige problematizar as características visíveis relacionadas à sua aparência, situação econômica e social numa perspectiva histórica, construindo, a partir desse olhar sensível, novas formas de ver e viver no mundo do qual fazem parte.

\section{A construção de gênero na escola}

Partindo da necessidade de problematizar os lugares que mulheres e homens ocupam na sociedade atual, podemos colocar em perspectiva o papel desempenhado pela escola na construção e na perpetuação do modelo que constrói e fixa esses lugares, como sendo adequados para uns e não para outros. Sobre isso, as/ os docentes declaram que "as construções sociais estão dentro da escola, e a gente mesmo precisa ter cuidado com isso, porque a gente mesmo às vezes brinca com o aluno e essas brincadeiras reforçam o preconceito e reforçam o desrespeito com o outro" (Paulo). Ou ainda: "a menina já tem que ter um caderno mais arrumadinho, a gente já carrega isso pra dentro da escola"; "se você elogia a letra de um aluno, o pessoal fica gozando...e a gente precisa combater isso"; "tem isso de isso não é coisa de menina, isso não é coisa de menino” (Marília). Enfim, falas que conduzem para o entendimento dos gêneros como construção relacional entre ser homem e ser mulher. Tais aspectos são defendidos por autoras como Judith Butler (2015), que afirma que o gênero se constrói por diferentes discursos os quais, para além 
de descrevê-los, atuam formando o que ele é. O gênero de cada criança, ao nascer, já aparece vinculado à sua genitália de forma contundente, como se tivesse sua origem a partir de um pênis ou uma vulva, quando não se pode mais negar que essas construções se dão por meio dos reiterados discursos (hetero)normativos que nos dizem cotidianamente como ser uma "mulher de verdade" ou um "homem de verdade".

Segundo o professor Cristiano, "quando a gente tem casos de gêneros distintos, de opções sexuais, o desrespeito aflora mais". Esse professor relata o caso de um aluno, numa turma de faixa etária de cerca de 11 anos de idade, que "tinha um corpo de menino, mas se identificava como menina e assumiu essa identidade, e os outros faziam piadas, brincadeiras entre si, ou outros brincavam com desrespeito", e reforça que, nesses casos, em que o desrespeito "aflora" ele precisa ser combatido mais efetivamente. Nas respostas e comentários, as/os entrevistadas/os ressaltam que é comum entre as/os docentes, de uma forma geral, a falta de conhecimento, por exemplo, sobre os processos de transgeneridades ${ }^{4}$. No exemplo utilizado, o professor afirma que "muitos colegas e funcionários da escola não sabiam como tratar esse aluno", chamando-nos a problematizar as oportunidades de discussão que as/ os docentes têm a respeito das múltiplas possibilidades de gênero, para além dos binarismos que compõem a norma padrão e os exercícios possíveis da sexualidade para além da heterossexualidade compulsória.

A esse respeito, Vencato $(2014$, p. 29) ressalta a importância da discussão na formação de professoras/es:

Não é novidade nos cursos de licenciatura a ausência, para a formação de docentes, de subsídios que lhe proporcionem a construção de um arcabouço teórico-metodológico que lhes ajude a lidar com as diferenças. Essa ausência se amplia ainda mais quando a diferença refere-se a questões de gênero, das sexualidades - ou orientações sexuais, termo mais comumente (re)conhecido na arena das políticas públicas - e da raça/etnia.

As/os docentes entrevistadas/os percebem, de forma efetiva, que a construção de gênero se dá nos espaços das escolas em que cada uma/um atua. Também reconhecem o incômodo diante de situações nas quais esse estabelecimento de papéis dirigidos a um ou a outro gênero binário se converte em recursos discriminatórios, em meios opressivos contra aquelas/aqueles que não se enquadram às normas e regras sociais previamente estabelecidas. Segundo Butler (2018, p. 41), "a precariedade está, talvez de maneira óbvia, diretamente ligada às normas de gênero, uma vez que sabemos que aqueles que não vivem seu gênero de modos inteligíveis estão expostos a um risco mais elevado de assédio, patologização e violência”. 
De acordo com o professor Paulo, os lugares estão marcados. Como, na escola, essas marcações não estão sendo colocadas sob suspeita, são pouco questionadas: "para o menino, é o lugar da rua, a menina é o lugar da casa. Então, eu acho que essa marca da nossa sociedade, ainda, ela acaba por definir isso". Os lugares de gênero parecem confirmados na escola, tanto para meninos quanto para meninas. Porém, identificar esse processo não garante a atuação nele, ou seja, parece que confirmam o que já sabem e, ao encontrarem essa confirmação, não se sentem chamados a atuar sobre ela. A professora Marília corrobora com a afirmação do colega, dizendo que "ela é mais cobrada, ela é mais vigiada mesmo", referindo-se à condição em que as meninas são colocadas em seus cotidianos, incluindo-se, aí, a escola.

As/os docentes chamam a atenção também para a vigilância promovida pelas/os próprias/os professoras/es, quando parte destas/es assume o discurso que naturaliza a heteronorma, tendo efeito de controle sobre os corpos, o que é exemplificado na fala de Paulo: "Não adianta fazer o discurso politicamente correto $e$ chegar na sala de aula e falar: 'você fez isso, ah veado!', e a gente vê isso na escola". A professora Ana argumenta, ainda, que essa construção é aliada à discriminação, muitas vezes presente, sobretudo, no curso noturno de sua escola:

No noturno, a gente percebe muito. Que ainda tem: "não, isso não é coisa de homem." [...] É o chorar. "Nossa, fulano... Nossa, isso não é coisa de homem, não. Homem não chora, não". E se a gente for parar pra pensar, esse tipo de comentário, ele já vem recheado de muito tipo de preconceito. Eu sinto por parte de alguns professores algumas piadas que a gente... meio que... aceita como comum entre, quando você está falando, quando vários homens estão conversando e tudo... Mas, principalmente, a gente percebe o desviar do assunto. É mais fácil não abordar do que enfrentar. É mais fácil você em momento algum se indispor. Mas isso é muito uma postura de direção. Pra que promover um debate?

O professor Cristiano também contribui para a discussão, ao trazer o relato sobre a presença dessas falas em sua escola:

E a questão das piadinhas, isso também é muito comum, é muito comum: "Não, isso é coisa de mulher, isso é coisa de homem"; "ó, não abraça o colega não que isso é coisa de viado"; "ó, pô, você é viadinho, pelo amor de Deus, vira homem". O "vira homem", então, você escuta cotidianamente na escola aluno falando com outros alunos e professor na hora da aula.

O professor Paulo complementa, dizendo também a respeito de tais práticas na escola em que atua: "lá a gente escuta professor falando com aluno: 'vira homem"', traduzindo e reafirmando práticas as quais reforçam o modelo binário que está imposto na escola, ao declarar que existe uma forma de ser homem, não várias 
formas de ser, além de outras opções e possibilidades para além do que se configura como ser homem.

Retornando às falas da professora Ana, ela constrói várias situações que nos permitem problematizar as relações em sua escola, envolvendo alunas/os e professoras/es, cujas posições de discriminação às vezes se confundem, se repetem e/ou coincidem. Quem educa também deseduca, ou educa para o preconceito, quando deixa de combater as posturas e os discursos de discriminação. Também chama a atenção para o que é comentado por outras/os docentes a respeito da prática de ignorar o ocorrido, o que se ouve, fingir que não aconteceu e deixar como está, sugerindo, inclusive, ser esta uma postura da direção da escola que, segundo ela, prefere se abster a tomar posições contrárias às práticas sexistas e homofóbicas.

Ela nos conta, ainda, de outra prática de sua escola: "a chamada é separada: meninos primeiro, meninas depois. [...] É estranho esse tipo de organização. Porque, se você segue a questão alfabética, é o mais correto. É o lógico". O gênero é uma forma de organizar o social. Assim como a fila ou a ordem alfabética dos diários, o gênero pode ser utilizado para organizar a realidade. Segundo Larissa Pelúcio (2014, p. 114),

O desafio de se trabalhar fora dos marcos identitários e das referências binárias relativas aos gêneros e à orientação sexual é exigente, pois demanda torções na nossa forma de perceber as dinâmicas sociais que oferecem esses termos classificatórios capazes de definir e fixar identidade.

Nesse sentido, cabe, então, questionar: o que faz alguém definir essa divisão como organização de uma burocracia escolar? Como investir em outras maneiras de lidar com os corpos sem a manutenção da divisão binária? Essas são questões que incomodam, ou que deveriam incomodar, as/os professoras/es que estão cotidianamente participando da reprodução dessas separações autoritárias do gênero. As/os professoras/es reconhecem sua formação social enquanto sujeitos e como isso é atravessado pelo gênero, ao mesmo tempo em que reconhecem também que a escola é o local de pensar e investir em outras formas de ser e estar no mundo.

\section{A insegurança docente: "não me sinto preparada/o para tratar esses assuntos"}

O roteiro utilizado nos grupos focais, elaborado a partir das respostas dos questionários, trazia para a discussão o sentimento de despreparo que professoras e professores afirmaram vivenciar. Em muitos momentos de suas declarações, 
deixaram claro que existe demanda por formação, assim como a possibilidade e a necessidade de discutir relações de gênero e sexualidades na escola. Durante esses encontros, quando vieram à tona as respostas que deixavam clara essa sensação de despreparo, uma nova questão emergiu, quando o professor Paulo afirma:

[...] quanto à falta de capacitação, eu acho que, sim, falta capacitação, mas falta principalmente interesse e disposição pra se colocar o debate porque muitas vezes essa capacitação é oferecida, mas não há um interesse pela procura dessa capacitação.

\section{Já o professor Cristiano complementa:}

Eu penso que falta realmente vontade e falta, às vezes, [...] conhecimento e falta também a pessoa querer fazer esse trabalho porque muitas vezes a pessoa, ela já tem determinados preconceitos, determinados pensamentos relacionados às discussões... relacionados à diferença, a gênero e outras mais, e a partir dessa vontade dela de não abordar esse assunto porque vai ser polêmico, vai trazer determinadas situações pra sala de aula, ela simplesmente não aborda. $E$ talvez por isso falte o interesse na capacitação porque a pessoa realmente não quer trazer pra sala de aula algo que é polêmico.

Não é possível simplificar as decisões e as atitudes das/dos docentes a um senso comum, de "quero ou não quero", pois a possibilidade de formação vem associada a vários outros fatores presentes na vida cotidiana dos sujeitos. Ser professora e professor traz consigo o ser mulher/homem, mãe/pai, esposa/o, namorada/o, amiga/o, estar muitas vezes em mais de uma escola ou outro espaço profissional, que não apenas à docência, espaços de lazer e prazer, viagens, família e tantas outras possibilidades de viver no mundo que cada pessoa traz em si e para si. A esse respeito, Antônio Nóvoa (1992, p. 12-13) afirma que

[...] a formação de professores tem ignorado, sistematicamente, o desenvolvimento pessoal, confundindo "formar" e "formar-se", não compreendendo que a lógica da atividade educativa nem sempre coincide com as dinâmicas próprias da formação [...] Urge por isso (re) encontrar espaços de interação entre as dimensões pessoais e profissionais, permitindo aos professores apropriar-se dos seus processos de formação e dar-lhes um sentido no quadro das suas histórias de vida.

Podemos inferir, portanto, que há demanda real e extensa por formação, mas há, ainda, a necessidade de olhar com sensibilidade para as questões subjetivas das/dos docentes, que as/os formam e transformam em professoras/es. Nóvoa (1992) considera que os indivíduos trazem consigo suas bagagens emocionais, culturais, religiosas e outros fatores de formação que, juntos, constituem cada uma/um. A formação está em diálogo com esses aspectos que constituem cada indivíduo, que não pode e nem consegue despir-se totalmente disso, que é parte da sua individua- 
lidade, em pouco tempo ou de um momento para o outro. Sobre os professores, Marília diz: "Eles têm a opinião formada e ela tem que se despir de todo o preconceito". Podemos dizer, então, que ser docente é um exercício de aprendizagem constante, em oportunidades que se somam no cotidiano de cada sujeito, enquanto este se forma e se transforma como ser humano e profissional.

A professora Ana insiste a respeito da necessidade de formação, seja na graduação, seja na formação continuada. A docente relata ser comum ouvir de alunas/ os e na mídia termos cujo significado ela desconhece, demonstrando, também, a preocupação com a linguagem que chamou de "politicamente correta", pois " $a$ cada dia a gente ouve a mesma coisa sendo dita de outro jeito". E complementa sua fala:

Falta, falta. Falta sim. Principalmente com relação ao que eu te falei, a questão dos termos, terminologia... Outro dia a gente estava comentando exatamente isso, como você chama uma criança que tem isso de uma forma não preconceituosa? Ah, mas a partir do momento que você rotula que tem isso, você já está sendo preconceituoso, então... Eu falei até na questão de necessidades especiais aqui dentro da escola. Um dia, eu lembro que eu comentei com uma amiga minha: nossa, vai ter um deficiente visual na Malhação. E ela: nossa, demorou tanto pra falar cego. Que eu parei e pensei assim, até que ponto o politicamente correto não está fazendo a gente deixar de discutir muita coisa? Porque, às vezes, você percebe na fala do outro, que tem um conhecimento maior, igual colocou aqui da questão do... amor afetivo (Ana).

Essas falas demonstram que não é o caso de apenas construir a formação numa dimensão pedagógica. É preciso investir em produção de saberes e, nesse sentido, pensar na criação de redes de formação, em que seja permitido atuar com o sujeito, sugerindo a troca de informações, experiências e partilha de saberes, na construção do espaço de formação.

Outra ideia que surgiu e suscitou debate foi a busca pela sensação de "estar preparado" para lidar com as questões que propusemos. Contudo, podemos indagar: que preparo é esse? Existe uma forma de estar preparada/o para esta ou outras abordagens ou o aprendizado se dá nas relações que se estabelecem no cotidiano? A esse respeito, Ferrari e Castro (2013b, p. 299) contribuem com nossa discussão, ao também indagarem:

É mesmo necessário que professoras e professores recebam formação para lidar com as homossexualidades nas escolas? Se for o caso, como deve ser essa formação? Por que foi possível formular essas questões? O que elas dizem de nós? Essas são reflexões que buscam problematizar o interesse pelas homossexualidades, pela formação docente, relacionando-as às questões da sexualidade e das homossexualidades e anunciando algumas possibilidades para a construção de olhares plurais e "desconstrutivos" sobre as identidades sexuais nas escolas. 
Variadas afirmações ouvidas durante esse trabalho de escuta e pesquisa sugerem que, nos currículos de formação de professoras/es, não havia, até recentemente, espaço para as discussões de gênero e sexualidades. De acordo com Kelly da Silva (2015), a abordagem do tema e sua introdução nos currículos de formação das universidades, na forma de disciplinas eletivas/optativas, é bastante recente e, como disciplina obrigatória, ainda é uma novidade e uma esperança.

Perguntadas/os se haviam discutido na formação acadêmica esses temas, a resposta foi negativa. Todas/os, sem exceção, afirmaram que nunca se depararam com a discussão durante seus processos de formação acadêmica. Segundo Cristiano, graduado em Educação Física:

Não que eu me lembre. Assim, de tratar o tema, de trazer a discussão, do tema gênero e sexualidade, não. Diferença, sim, uma discussão numa matéria de Educação Física adaptada, mas mais voltada pra questão do aluno deficiente.

Marília, professora de Geografia, lembrou que, em sua área de formação, havia poucas mulheres nas turmas: "e meu curso já é um curso que a maioria é homem, né? Eu lembro quando eu entrei eram quatro mulheres na sala. Então, a Geografia tem uma predominância masculina muito grande. Aí então não discutia mesmo”. E essa informação é reforçada por Paulo, ao dizer: "História também, na minha época, quando eu formei... Na minha época, o meu curso tinha mais homem”. É possível perguntarmos, por meio dessas falas: por que em turmas nas quais predominam estudantes do gênero masculino, espera-se que não haja a discussão relacionada a gênero e sexualidades, como sugerem a e o entrevistada/o? Será a discussão de gênero e sexualidades um assunto para docentes mulheres?

Pensando na formação dos conhecimentos, Silva Junior (2013, p. 71) afirma que "o reforço dos controles e das resistências encadeiam-se uns aos outros, segundo algumas grandes estratégias de saber e poder". Recorrendo também à perspectiva de desvelamento do que está implicado na sexualidade, como Foucault (2011, p. 100) defende, podemos ter, como um ponto de partida, a premissa de que vivemos ancorados em normas que impõem o binarismo de gênero. Estamos vendo esse processo acontecer nos cursos de formação, em que ainda temos áreas que são tidas como mais de mulheres e outras de homens. Segundo Kelly da Silva (2015), é possível perceber que as discussões de gênero e sexualidades estão chegando às instituições de formação de professoras/es, porém, ainda precisamos perguntar como isso está se dando nos diferentes conteúdos. A autora demonstrou, em seu trabalho, que, nos cursos de Pedagogia, as disciplinas já estão acontecendo, embora ainda haja demanda por mais espaço nos currículos desses cursos. 
Para Ferrari e Castro (2013b, p. 312):

O "tornar-se professor(a)" não é algo que se possa fazer apenas durante um curso de formação inicial ou através de cursos específicos de formação continuada. Esse é um processo constituído a partir de inúmeras experiências, construídas no movimento e nas mudanças que se dão ao longo do trajeto. Através da "viagem de formação", o(a) professor(a) constrói e reconstrói a sua subjetividade. Desse modo, as práticas de formação de professores(as) não só produzem sujeitos, mas instauram uma relação reflexiva do(a) professor(a) consigo mesmo(a).

Nesse sentido, Roney Polato de Castro (2014) argumenta a favor da problematização das relações entre os currículos de formação docente e as temáticas das relações de gênero e sexualidades, afirmando que isso deve ser feito "a partir de condições de emergência de redes discursivas que vem se delineando no plano político, de produção e conhecimentos e da vida cotidiana" (CASTRO, 2014, p. 73). É tempo de repensar esses currículos, trazendo para seus espaços porosos novas formas de discussão que possam fomentar a constituição de mais disciplinas e o trânsito dos temas em questão pelas áreas que já existem. Isso pode trazer enriquecimento e amplitude de abordagem aos cursos de formação.

\section{Considerações finais}

O conjunto das respostas demonstra que as/os professoras/es adquiriram, em algum momento da vida, um conhecimento que se refere às relações de gênero e sexualidade e conseguem fazer articulações com o seu fazer docente. Esse conhecimento é, ao mesmo tempo, um reconhecimento das contribuições teóricas das discussões de gênero e sexualidades. Para além disso, dizem também do processo de fabricação dos sujeitos, sejam como professoras/es ou como alunas/os. Elas/eles trazem à tona saberes sobre o que seria gênero e sexualidades e, assim, o que significa trabalhar com essas temáticas, acionando entendimentos de escola e educação.

A escola é esse espaço de fabricação dos sujeitos. Como gênero é um organizador social, ele está presente na escola, convocando professoras/es a trabalhar com ele, mesmo que não tenham clareza disso. Nesse sentido, o que é apontado neste trabalho é que fazemos coisas com os gêneros e as sexualidades, que somos subjetivados pelos saberes que nos povoam e que nos dizem dos sujeitos. Na sala de aula, isso se soma às subjetividades de professoras/es, numa posição de sujeito que convoca a questionar: "quem eu penso que sou?", "quem eu penso que meus alunos e alunas são?" e "quem eu quero ser?", assim como "quem eu quero que meus 
alunos e alunas sejam?". O trabalho das/os professoras/es está implicado nesse processo de investimento nos sujeitos. Não é por acaso que trazem para o debate a associação com outras categorias como "diferenças", "diversidade", "preconceito", conceitos que se somam às discussões e que fornecerão o entendimento de gênero e sexualidade; conceitos e saberes que são atravessados por relações de poder, como nos lembra Foucault (2011).

O que estas/estes professoras/es nos dizem é que as escolas trabalham com as relações de gênero e sexualidades de diferentes maneiras. Saem e nos tiram do lugar de reclamação, que marca esse campo, de que a escola não discute e, portanto, não trabalhamos com gênero e sexualidade nas escolas. Não negam que as escolas - traduzidas nas suas ações, já que escola diz do conjunto da ação docente em articulação com currículo, com a relação ensino/aprendizagem, etc. - têm dificuldades em discutir essas questões, mas isso não significa que não fazem nada. Nesse sentido, o que a pesquisa demonstrou é que a questão mais importante não é saber se fazemos ou não, mas o que fazemos sem, muitas vezes, nos darmos conta de que estamos construindo ideias e sujeitos. As/os docentes abordam os temas referentes às relações de gênero e sexualidades porque reconhecem que as/os alunas/ os estão interessadas/os nas temáticas, elas dizem delas/es e trazem as questões. As discussões de gênero e sexualidade suscitam a atenção para aquilo que "invade" a escola, num olhar que se traduz na identificação das pequenas possibilidades de fugas e resistências, micropoderes cotidianos que nos constituem, sendo possível pensar outras formas de ser e estar no mundo.

Por isso, acreditamos na potencialidade deste trabalho ao refletir sobre o fazer/ser professoras/es em meio às práticas cotidianas, que devem ser retomadas e problematizadas para pensar outras formas de ser escola, de ser educação, de ser sujeito. Existem resistências nas escolas, seja no voltar o olhar para o seu próprio fazer docente para colocar sob suspeita o que pensamos e como agimos, seja no voltar o olhar para o que as/os alunas/os estão propondo nos gestos, nas conversas, nas dúvidas e que está presente no conjunto do que são as relações de gênero e sexualidades. Podemos, por fim, perceber, nas escritas das/dos professoras/es, como o gênero e seus atravessamentos com a sexualidade estão diretamente ligados à noção de verdade dos sujeitos, como vamos nos tornando sujeitos de uma sexualidade. 
1 As quatro questões foram: você aborda, durante suas aulas, os temas referentes a relações de gênero e sexualidades? Se a resposta foi afirmativa, quais temáticas são abordadas dentro desses temas? A escola é um bom espaço para as discussões de gênero e sexualidades? Você identifica problemas, preconceitos, discriminações, ligadas a gênero e sexualidades em suas aulas? Descreva um pouco o que tem observado.

2 Todos os nomes são fictícios, respeitando o anonimato das/dos participantes.

3 O itálico está sendo usado para diferenciar excertos da pesquisa de citações bibliográficas.

4 Utilizamos o termo "transgeneridades", seguindo a definição proposta por Magno (2017, p. 12), como termo "guarda-chuva", referindo-se de forma genérica ao conjunto de identidades e/ou práticas de gênero que rompem as expectativas de identificação e/ou performance baseadas no sexo/gênero designado ao nascimento, englobando, assim, travestis, transexuais, crossdressers, pessoas de gênero não-binário, entre outras.

\section{Referências}

BUTLER, Judith. Corpos em aliança e a política das ruas: notas para uma teoria performativa de assembleia. Rio de Janeiro: Civilização Brasileira, 2018.

BUTLER, Judith. Corpos que pesam: sobre os limites discursivos do "sexo" In: LOURO, Guacira Lopes (org.). O Corpo Educado. 3. ed. Belo Horizonte: Ed. Autêntica, 2015, p. 151-168

BUTLER, Judith. Problemas de gênero: feminismo e subversão da identidade. Trad.: R. Aguiar. Rio de Janeiro: Ed. Civilização Brasileira, 2015.

CARDOZO, Guilherme Lima. O pós-estruturalismo e suas influências nas práticas educacionais: a pesquisa, o currículo e a "desconstrução". Pensares em Revista, São Gonçalo-RJ, n. 4, jan./jul., p. 118-134. 2014.

CASTRO, Roney Polato. Experiência e constituição de sujeitos docentes: relações de gênero, sexualidades e formação em Pedagogia. Tese de Doutorado. Programa de Pós-Graduação em Educação, Universidade Federal de Juiz de Fora. Juiz de Fora-MG, 2014.

COSTA, Maria Vorraber. Apresentação. In: COSTA, Maria Vorraber (org.). Caminhos Investigativos: novos olhares na pesquisa em educação. Porto Alegre: Ed. Mediação, 1996.

FERRARI, Anderson; CASTRO, Roney Polato. "Nossa! Eu Nunca Tinha Parado pra Pensar Nisso!" - Gênero, sexualidades e formação docente. Interfaces da Educação. Paranaíba, v. 3, n. 7, p. 68-83, 2013a.

FERRARI, Anderson; CASTRO, Roney Polato. “Quem está preparado pra isso?" Reflexões sobre a formação docente para as Homossexualidades. Práxis Educativa. Ponta Grossa, v. 8, v. 1, jan./ jun, p. 295-317, 2013b.

FOUCAULT, Michel. História da sexualidade I: a vontade de saber, 3. ed. Rio de Janeiro: Ed. Graal, 2011.

FOUCAULT, Michel. A coragem da verdade: o governo de si e dos outros. São Paulo: Editora WMF Martins Fontes, 2011a. 
LOURO, Guacira Lopes. Gênero, sexualidade e educação: uma perspectiva pós estruturalista. Petrópolis: Vozes, 1997.

MAGNO, Cláudio. "Identidades de gênero não-binárias": uma análise ciborgue da performatividade de gênero em narrativas digitais. Dissertação de mestrado defendida em agosto de 2017, aguardando publicação. Programa de Pós-Graduação em Psicologia, Universidade Federal de Minas Gerais, Belo Horizonte-MG. 2017.

MOREIRA, Antônio Flávio Barbosa; CANDAU, Vera Maria. Currículo, conhecimento e cultura. In: BEAUCHAMP, Jeanete; PAGEL; Sandra Denise; NASCIMENTO, Aricélia Ribeiro do. (org.). Indagações sobre currículo. Brasília: Ministério da Educação, Secretaria de Educação Básica, p. 17-48, 2007.

NÓVOA, Antônio. Formação de professores e profissão docente. 1992. Disponível em: http://repositorio.ul.pt/bitstream/10451/4758/1/FPPD_A_Novoa.pdf. Acesso em: 15 out. 2018.

PELÚCIO, Larissa. Desfazendo o Gênero. In: MISKOLSI, Richard; JÚNIOR, Jorge Leite (org). Diferenças na educação: outros aprendizados. 1. ed. São Carlos: Ed. EdUFSCar, p. 46-69. 2014.

RODRIGUES, Alexsandro. Sexualidade(s) e currículo(s): práticas cotidianas que nos atravessam produzindo experiências. Tese de Doutorado em Educação. Faculdade de Educação da Universidade Federal do Espírito Santo. Vitória: UFES. 2009.

SANTOS, Lucíola; PARAÍSO, Marlucy Alves. Dicionário crítico da educação: currículo. Presença Pedagógica, Belo Horizonte, v. 2, n. 7, p. 82-84, 1996.

SCOTT, Joan. Gênero: uma categoria útil de análise histórica. Porto Alegre: Educação e Realidade, v. 20, n. 2, jul./dez., 1995.

SIERRA, Jamil Cabral. Marcos da vida viável, marcas da vida vivível: o governamento da diversidade sexual e o desafio de uma ética / estética pós-identitária para teorização político-educacional LGBT. Curitiba, 2013. Tese de Doutorado em Educação - Educação da Universidade Federal do Paraná.

SILVA, Kelly. Currículo e gênero: a sexualidade na formação docente. Curitiba: Ed. Appris, 2015.

SILVA JUNIOR, Jonas Alves da. Diversidade e educação: apontamentos sobre sexualidade e gênero na escola. In: RANGEL, Mary (org). A escola diante da diversidade. Rio De Janeiro: Wak Editora, 2013.

VEIGA NETO, Alfredo. Há teoria e método em Michel Foucault? Implicações educacionais. In: CLARETO, Sonia Maria; FERRARI, Anderson (org). Foucault, Deleuze e educação. 2. ed., ampliada e revisada. Juiz de Fora: Ed. UFJF, 2013.

VENCATO, Ana Paula. Diferenças na escola. In: MISKOLSI, Richard, JÚNIOR, Jorge Leite. (org). Diferenças na educação: outros aprendizados. São Carlos: Ed. EdUFSCar, 2014. p. 92-117. 